Universities Council on Water Resources

Journal of Contemporary Water RESEARCH \& Education

ISSUE 130, PAGES 36-40, MARCH 2005

\title{
FEMA and Mitigation: Ten Years After the 1993 Midwest Flood
}

\author{
Norbert Schwartz \\ Director of Federal Insurance and Mitigation Division \\ Federal Emergency Management Agency, Region V
}

I n 1993, spring came in like a lion, but refused to go out like a lamb. Day after day, heavy rainfall blanketed the nation's midsection. Summer arrived, and driving rains continued to soak the Midwest. Rivers and streams crept higher and higher, overflowing their banks and flowing across a nine-state region that stretched more than 800 miles long and 500 miles across at its widest point. In some locations, flooding lasted for nearly 200 days. As many as 150 major rivers and tributaries were affected, and 14 rivers reported record crests. Several of these riversthe Mississippi and the Missouri-are among the largest in the nation.

Of more than 1,000 levees built to hold back the floodwaters, 800 were breached, leaving at least 75 entire communities submerged. According to a report issued by the National Weather Service, 50 people died as a result of the floods; tens of thousands of people were evacuated; at least 10,000 homes were destroyed; and damages approached $\$ 15$ billion.

The Midwest Flood of 1993 ranks sixth among FEMA's list of top ten disasters. A total of 534 counties in nine states received federal disaster aid, and FEMA provided more than $\$ 1.17$ billion in disaster assistance. According to Census Bureau figures, there were more than 12.7 million households in those states that flooded during the spring and summer of 1993. When the rains began in April of 1993, National Flood Insurance Program (NFIP) had underwritten 87,456 policies in the affected states. By the time the floodwaters receded and all insurance claims were closed, the NFIP had paid more than $\$ 319$ million for almost 16,800 losses.

\section{Major FEMA Program Initiatives (1993-Present)}

Since 1993, FEMA has encouraged the development and implementation of mitigation programs to lessen the impact of future floods on people's lives and property. By encouraging safe building within floodplains, removing homes altogether from floodplains, and enforcing effective building codes, FEMA and its partners can lessen the impact on lives and communities. These and other FEMA mitigation programs aimed at supporting community efforts to reduce future flooding in the Midwest are summarized briefly below.

\section{National Flood Insurance Program (NFIP)}

Although it is not new, the most widespread flood mitigation program is the National Flood Insurance Program (NFIP). Nearly 20,000 communities across the United States and its territories participate in the NFIP by adopting and enforcing floodplain management ordinances to reduce future flood damage. In exchange, the NFIP makes federallybacked flood insurance available to homeowners, renters, and business owners in these communities. Community participation in the NFIP is voluntary.

Flood insurance is designed to provide an alternative to disaster assistance by reducing the escalating costs of repairing damage to buildings and their contents caused by floods. Flood damage is reduced by nearly $\$ 1$ billion a year nationally through communities implementing sound floodplain management requirements and property owners purchasing of flood insurance. Additionally, buildings 
constructed in compliance with NFIP building standards suffer approximately 80 percent less damage annually than those not built in compliance. And, every $\$ 3$ paid in flood insurance claims saves $\$ 1$ in disaster assistance payments.

In addition to providing flood insurance and reducing flood damages through floodplain management regulations, the NFIP identifies and maps the nation's floodplains. Mapping flood hazards creates broad-based awareness of the flood hazards and provides the data needed both for floodplain management programs and to actuarially rate new construction for flood insurance.

\section{Hazard Mitigation Grant Program (HMGP)}

Authorized under Section 404 of the Stafford Act of 1988 and amended in 1993, the Hazard Mitigation Grant Program (HMGP) provides grants to states and local governments interested in implementing long-term hazard mitigation measures in the wake of a major disaster declaration. The purpose of the program is to reduce the loss of life and property due to natural disasters and to enable mitigation measures to be implemented during the immediate recovery period following a disaster declaration. HMGP funding is only available in states after a presidential disaster declaration. Eligible applicants are state and local governments, Indian tribes or other tribal organizations, and certain private non-profit organizations. Individual homeowners and businesses may not apply directly to the program; however, a community may apply on their behalf. HMGP funds may be used to fund projects that will reduce or eliminate similar losses during future disasters. Projects must provide a long-term solution to a problem (e.g., elevation of a home to reduce the risk of flood damages as opposed to buying sandbags and pumps to fight the flood). In addition, a project's potential savings must be more than the cost of implementing the project. Funds may be used either to protect public or private property or to purchase property that has been subjected to, or is in danger of, repetitive damage.

Acquisition of flood prone property was the main thrust of the HMGP program in the Midwest for several years following the flood of 1993. Several thousand structures were eliminated from the floodplains throughout the region, and the parcels have been returned to natural functions. In many of these areas, more recent flooding has occurred, resulting in non-disaster events.

\section{Flood Mitigation Assistance (FMA) Program}

FMA was created under a 1994 Flood Insurance Act to provide property owners with the resources necessary to prevent future flood losses. FMA provides funding to assist states and communities with the implementation of measures aimed at reducing or eliminating the long-term risk of flood damage to buildings, manufactured homes, and other structures insurable under the National Flood Insurance Program (NFIP). There are three types of grants available under FMA: Planning, Project, and Technical Assistance Grants. FMA Planning Grants are available to states and communities to prepare Flood Mitigation Plans. NFIP-participating communities with approved Flood Mitigation Plans may also apply for FMA Project Grants. A few examples of eligible FMA projects include: the elevation, acquisition, and relocation of NFIP-insured structures. Funding for the program is provided through the National Flood Insurance Fund, and FMA is funded at $\$ 20$ million nationally.

States are encouraged to prioritize FMA project grant applications that include repetitive loss properties. Since 2001, the FMA emphasis encourages states and communities to address target repetitive loss properties identified in the Agency's Repetitive Loss Strategy. These include structures with four or more losses and structures with two or more losses where cumulative payments have exceeded the property value. States and communities are also encouraged to develop plans that address the mitigation of these target repetitive loss properties.

\section{Pre-Disaster Mitigation (PDM) Program}

As a result of the success of the HMGP program and realization of the need for a program to support mitigation activities before a disaster event occurs, the Pre-Disaster Mitigation (PDM) program was created in 2000. The PDM grant program provides funds to help states and communities reach a higher level of risk management and reduction through hazard mitigation planning and the implementation of planned, pre-identified, cost-effective mitigation measures prior to a disaster event. The PDM program provides a significant opportunity to raise risk awareness and to reduce the nation's disaster 
losses. FEMA’s PDM program has received a $\$ 150$ million appropriation for fiscal years 2003 and 2004. Applicants compete nationally for available funding.

Mitigating repetitive flood losses has been a high priority. FEMA's Repetitive Loss Strategy focuses on the Nation's 10,000 repetitive loss properties(i.e., NFIP insured structures that have had four or more flood losses, or two or three losses that together exceed the building's value). Over the past 21 years, FEMA has paid out nearly \$1 billion in NFIP claims for these extreme cases. Nationally $2 \%$ of the structures account for 40 percent of paid losses. There is a push to remove these structures from the floodplains, elevate them above the reach of floodwaters, or apply other measures to reduce their exposure. The PDM program is a key component to this effort.

\section{Increased Cost of Compliance (ICC)}

If a flood substantially damages a home or business, the owner may be required to meet certain building requirements to reduce future flood damage before it is repaired. To help cover the costs of the mitigated repairs, the NFIP includes ICC coverage for all new and renewed flood insurance policies. Policyholders can get up to $\$ 30,000$ to help pay the costs to bring the structure into compliance with their community's floodplain ordinance. ICC payouts in the Midwest have gone to support elevation, relocation, demolition, and flood-proofing projects. The program is relatively new and underutilized, but it is a program in place that can be utilized by a flooded victim when the need arises.

\section{Map Modernization}

Accurately identifying the nation's floodplains is the first step to reduce the risk of loss. Although the NFIP's Flood Insurance Rate Maps have served the nation well for insurance, mitigation, and flood disaster relief, these paper panels have become obsolete and are cumbersome to update. The goal of FEMA's Map Modernization Plan is to upgrade the 100,000 panel flood map inventory. This major remapping is critical to efforts to reduce the exposure of people and property to flood hazards in the Midwest and throughout the nation.

This presidential initiative began in FY2003 with a budget of $\$ 150$ million and continues in FY2004 with a budget of $\$ 200$ million nationwide. This multiyear effort to update flood hazard information across the nation will cost nearly $\$ 1$ billion, but, in the end, communities will have access to accurate, webbased, easily maintained GIS products. More importantly, the GIS format of this product will increase its utility for planning and risk management.

Over a 5-year period, the 100,000 FIRM map inventory will be converted to digital format and will be available for over 14,000 communities. Additionally, approximately 13,700 new digital maps will be created for flood prone communities that do not currently have flood maps. FEMA is leveraging industry innovations and their best practices to modernize processes and products. Partnerships are being established with all levels of government to ensure that local government decision-makers have the flood risk information they need, when they need it.

One result of this activity is the recently released HAZUS MH module. This multi-hazard risk assessment and loss estimation tool can be used by a community to assess efficiently its risk to multiple hazards. It is anticipated that HAZUS MH will be a useful tool for facilitating mitigation and emergency management planning efforts across the country.

\section{Promotion of State and Local Mitigation Planning}

For years, disaster recovery was based on a disaster-response-driven system, where the only thought was to get the communities back on their feet as soon as possible. That rationale led to everincreasing disaster relief costs for communities, states, and the Federal government, as sites were damaged multiple times. After re-evaluating this strategy, Congress decided that FEMA should place more emphasis on the planning process to promote and support sustainable, disaster resistant communities. Toward this end, FEMA is working with state and local partners to meet the challenges of reducing future damages through mitigation planning.

The Disaster Mitigation Act of 2000 includes a mitigation planning section. Mitigation planning is a collaborative process whereby hazards affecting the community are identified, vulnerability to hazards assessed, and consensus reached on how to minimize or eliminate the effects of these hazards. Effective November 1, 2004, a mitigation plan approved by FEMA and the State is required from any community that wishes to obtain funding from HMGP to reduce 
potential damages. Approved mitigation plans are also required to receive project money for FMA and PDM programs, as well as select disaster assistance programs.

\section{Collaborative Efforts}

The anniversaries of significant flood events, such as the Midwest floods, provide excellent opportunities to re-focus the public's attention on the dangers they face from flooding, to educate communities on the importance of mitigation, and to encourage people to buy and keep flood insurance. Implicit in this effort is increased public involvement and personal responsibility for reducing risk. Broad partnerships among citizens, businesses, and planners keep mitigation alive as a top priority.

The Region V states of Illinois, Indiana, Michigan, Minnesota, Ohio, and Wisconsin have taken the initiative to establish interagency mitigation state advisory councils to coordinate statewide mitigation issues. In two states, the councils or boards were established by executive orders from the governors. For example, after the 1993 floods and subsequent acquisition program, the Illinois Emergency Management Agency (IEMA) organized the Interagency Mitigation Advisory Group (IMAG) to facilitate implementation of various mitigation programs. This group is composed of a variety of agencies, including: Illinois Department of Natural Resources, Illinois Historic Preservation Agency, Department of Commerce and Community Affairs, FEMA, the American Red Cross, and IEMA.

At the federal level, FEMA Region $\mathrm{V}$ has established the RISC Mitigation Sub-Committee, which is a committee of federal partners with overlapping interest in mitigation. The parent group is the Regional Interagency Steering Committee (RISC), whose mission is to coordinate all aspects of federal emergency management activities in particular regions. The Sub-Committee focusing on mitigation meets quarterly, and it provides a forum for federal participants to come together and share ideas concerning all facets of risk reduction. It is intended that the federal partners coordinate existing programs, eliminate duplication, develop comprehensive solutions, support state mitigation advisory councils, and present a united front for communities.

\section{Outreach Efforts}

FEMA is working to strike a balance between communicating an effective, all-hazards message to the public and maintaining its messages about specific risks, such as floods. However, it is not enough to heighten awareness of risks. FEMA must also convince citizens to take appropriate actions to protect themselves from harm. And equally important is the ability to demonstrate and measure effective communication and outreach efforts.

To support this effort, FEMA has released a userfriendly, web-based mitigation success stories database. Mitigation success stories not only provide communities with information on reducing risk, they encourage communities to pursue mitigation. These stories demonstrate that communities can have some control over the hazards they face, and that resources are available to help them reduce their vulnerability. Use of the database will promote mitigation.

As part of an outreach campaign, FEMA has developed a series of mitigation planning "how-to" guides to assist states, communities, and tribes in enhancing their hazard mitigation planning capabilities. These glossy, thorough, and high-quality guides are designed to provide the type of information state and local governments need to initiate and maintain a planning process that will result in safer communities. These guides are applicable to states and communities of various sizes and varying ranges of financial and technical resources. It is intended that these guides serve a vital role in establishing a planning platform for all loss reduction measures.

\section{Conclusion}

These are exciting times for all of us. From basic mitigation activities such as purchasing flood insurance or elevating a home, to communicating risk, to providing technically complex planning tools, FEMA, teaming up with other federal partners and the states, is actively working with at-risk communities to facilitate risk reduction and shape a disaster-resistant nation. It is our common goal the next time a similar 1993 flood occurs, the resulting event will be minimized to the maximum extent possible. 


\section{Author Bio and Contact Information}

Norbert Schwartz is the Division Director for the Federal Insurance and Mitigation Division, FEMA Region V, part of the Department of Homeland Security. He has oversight for several programs within a six state region including the National Flood Insurance Program and other pre and post-disaster hazard mitigation programs. Previous to his management position, he served as a FEMA Regional coordinator for a dam safety program and the National Flood Insurance Program that included flood risk mapping, floodplain management, and flood insurance. Early in his career, he worked as a hydrologic and hydraulic engineer for the Army Corps of Engineers in Chicago. Mr. Schwartz received a MS in Water Resource Engineering from the University of Maryland in 1978 and BA from University of Michigan.

\section{References}

Larson, L.W. 1993. "The Great Midwest Flood of 1993," Natural Disaster Survey Report. Kansas City, MO: National Weather Service.

US Department of Homeland Security, Federal Emergency Management Agency (FEMA). 2003. The 1993 Great Midwest Flood: Voices 10 Yeas Later. Washington, DC: FEMA. 